\title{
ENSINO DE QUIIMICA NO TÉCNICO DE NIVEL MÉDIO INTEGRADO EM INFORMÁTICA: UMA PROPOSTA DE ENSINO CONTEXTUALIZADO E INTERDISCIPLINAR
}

\author{
Alexandre Geraldo Viana Faria, Rodrigo Andrade Cardoso, Rafael Rodrigues Godoy \\ Instituto Federal de Mato Grosso do Sul \\ DOI: 10.15628/rbept.2019.7667
}

Artigo submetido em ago/2018 e aceito em abr/2019

\begin{abstract}
RESUMO
A interdisciplinaridade e a contextualização são meios pedagógicos para promover uma aprendizagem mais eficaz, ambos estão presentes em documentos que norteiam a modalidade de ensino integrado, comtemplada na Educação Profissional e Tecnológica que se expande juntamente com os Institutos Federais. Nesse sentido, o presente trabalho objetivou apresentar uma proposta didática contextualizada e interdisciplinar para o ensino de Química no curso Técnico Integrado de Nível Médio em Informática do Instituto Federal de Educação Ciência e Tecnologia do Mato Grosso do Sul. A proposta se desenvolveu com uma turma do Técnico em Informática em conjunto com um professor de Informática, na qual, por meio da descrição de componentes de computadores, houve a intervenção tanto do professor de Química, no ensino de Tabela Periódica, quanto pelo professor de Informática, no ensino das funções e características de cada periférico. Pelo relato dos estudantes e do professor de Informática envolvido na proposta, pôde-se notar relevante interesse dos discentes em aprofundar seus conhecimentos acerca dos assuntos envolvidos, o que nos leva a crer que nossa proposta foi adequada às propostas didáticas de interdisciplinaridade $e$ contextualização.
\end{abstract}

Palavras-Chave: Ensino de química. Contextualização. Interdisciplinaridade. Educação Profissional.

\section{TEACHING OF TECHNICAL CHEMISTRY OF AVERAGE LEVEL IN COMPUTING: A PROPOSAL OF CONTEXTUALIZED AND INTERDISCIPLINARY TEACHING}

\begin{abstract}
This article is the result of an interdisciplinary work applied to students of a second year of the Technical Course in Informatics Integrated to High School, at Federal Institute of Rio Grande do Sul, Campus Farroupilha, during the year of 2018. The project, entitled "Shake your mind and read books: an invitation to read Shakespeare", aimed to offer access and contact with the literary work "Hamlet", written by the English writer William Shakespeare, stimulating the development of reading comprehension, writing and oral production, instigating creative expression, as well as using forms of digital language. The work, of an interdisciplinary nature, involved the curricular components of History, Portuguese Language and English Language, according to the precepts of the Pedagogical Project of the Course and the Integrated Curriculum.
\end{abstract}

Keywords: Reading. Interdisciplinarity. Shakespeare. Professional education. 


\section{INTRODUÇÃO}

O curso Técnico Integrado ao Ensino Médio em Informática (TIEMI) faz parte da Educação Profissional e Tecnológica (EPT), que se desenvolve a passos largos no Brasil com os Institutos Federais (IF's). Historicamente, a EPT sempre teve o intuito de formar profissionais capacitados para trabalhar em áreas tecnológicas e, atualmente, este segmento possui grande preocupação com a formação crítica do cidadão, preparando-o não somente para o mundo do trabalho, mas para questionar e analisar a sua realidade, de forma racional, focando no âmbito regional (PACHECO, 2011). Dentre as modalidades da EPT, a integrada ao Ensino Médio apresenta características que possibilitariam uma maior articulação entre as disciplinas do núcleo comum e as tecnológicas. Para que isso possa ocorrer de forma eficaz, Ramos (2008) propõe que seja utilizada tanto a interdisciplinaridade quanto a contextualização.

Os documentos oficiais apontam que abordagens pedagógicas interdisciplinares e contextualizadas são recursos didáticos essenciais à prática docente, considerados um meio eficaz de aprendizagem. A interdisciplinaridade é apresentada como forma de se evitar a fragmentação do conhecimento, não permitindo que as disciplinas sejam mostradas de forma compartimentada. Também nos documentos, a contextualização é proposta com o intuito de atribuir significações aos conteúdos, destacando situações em que problemas reais são apresentados aos alunos (BRASIL, 1999, 2002a e 2006).

A contextualização é uma questão muito discutida por diversos professores como um meio para se ensinar ciência a partir da realidade dos discentes, viabilizando uma base para a formação crítica do cidadão. Dessa forma, Silva (2007) propõe que a contextualização pode assumir três diferentes propostas: a de exemplificação; a de abordagem de uma questão problematizadora e a de ação efetiva na sociedade.

Diante desse panorama, questionamo-nos: como elaborar uma abordagem interdisciplinar e contextualizada para aulas de Química no curso 
TIEMI do Instituto Federal de Mato Grosso do Sul (IFMS) campus Coxim? Visando responder a essa questão, buscamos conhecer o que documentos oficiais trazem sobre ensino integrado, investigamos os documentos oficias do IFMS à procura de questões que tratam sobre contextualização e interdisciplinaridade, buscamos investigar no Projeto Pedagógico do Curso de TIEMI as ementas das disciplinas específicas e das de Química para possíveis inter-relações. Balizados por esses documentos, desenvolvemos e aplicamos uma proposta didática contextualizada e interdisciplinar para o ensino de Química no curso de Informática. A análise dos resultados indica que os recursos pedagógicos utilizados, auxiliaram a prática docente em promover maior interesse discente por conteúdos de Química e Informática, mais especificamente das disciplinas de Química 1 e Organização de Computadores.

\subsection{INTERDISCIPLINARIDADE}

A apresentação dos conteúdos durante o Ensino Médio deve ocorrer de modo a evitar a fragmentação dos saberes, para não resultar em disciplinas isoladas. Uma possível proposta didática para superar esta fragmentação seria relacionar diferentes áreas do conhecimento de modo interdisciplinar, evitando o reducionismo da ciência. Vários autores discutem acerca da concepção de interdisciplinaridade, sem chegar a um consenso sobre uma possível definição (THIESEN, 2008). Mesmo assim, apesar desse conceito ainda estar em construção e, independente da definição que cada autor assuma a interdisciplinaridade sempre ocorre no sentido de relacionar disciplinas, visando superar 0 isolamento das ciências e das informações produzidas por elas, propondo uma relação de construção de conhecimento entre especialistas de áreas distintas por meio da interação entre as disciplinas dentro de um mesmo projeto.

A adoção de uma abordagem interdisciplinar no Ensino Médio é uma das indicações dos documentos oficiais. De acordo com os Parâmetros Curriculares Nacionais (PCN's), a interdisciplinaridade pode ser uma prática adequada para que ocorra uma aprendizagem eficiente, pois quando existe a interação dos conhecimentos, em que as disciplinas são relacionadas por 
meio de atividades ou projetos de estudos, além de pesquisas e ações, o aluno é exposto à complexidade do processo de construção do conhecimento (BRASIL, 1999).

A necessidade de relacionar ciências é intrínseca ao ser humano para um resultado eficaz da aprendizagem. Em meio a um mundo globalizado, com o advento de novas tecnologias e a alta velocidade de acesso a diversos tipos de informação, a ideia de rede de conhecimentos é facilitada. Assim também poderiam ser os currículos das diferentes disciplinas, apresentandoas articuladas entre si. A representação de uma rede ou teia de significações sugere uma boa imagem para compor o trabalho interdisciplinar.

Os conteúdos discutidos nas aulas de Química permitem vasta possibilidade de interações com as outras disciplinas do Ensino Médio. Temas de grande relevância, como o meio ambiente e saúde, podem representar propostas para se trabalhar a interdisciplinaridade. É possível notar que uma das interações mais exploradas no ensino de Química, ao longo do Ensino Médio, ocorre com a disciplina de Física, haja vista que, dos três anos de Ensino Médio, um é dedicado ao estudo de Físico-química. Outra interação que nos parece evidente é durante o estudo de bioquímica, que relaciona a química à biologia. Física e Biologia naturalmente se apresentam com características interdisciplinares a Química, porem conteúdos de Tecnologia de Informação não se mostra com possibilidade interdisciplinares tão evidentes. Por esse motivo, como meio de relacionar os conteúdos de Química com os de informática, procuramos nos ater as questões do cotidiano do profissional dessa área.

\subsection{CONTEXTUALIZAÇÃO}

A contextualização no ensino de Ciências é discutida por diversos educadores como uma tendência que possibilita ao discente uma base para a formação crítica do cidadão, concomitante à apreensão dos conteúdos. A Contextualização é considerada um meio para se ensinar conceitos científicos ligados à realidade dos discentes, podendo ser vista como um recurso pedagógico, bem como um norte no processo de ensino e aprendizagem. Assim, a contextualização passa pelas relações estabelecidas 
entre o que o aluno sabe, sobre o contexto a ser estudado, e os conteúdos específicos que dispõem de explicações para o entendimento desse contexto (SILVA, 2007). Para tanto, fica evidente a necessidade de, primeiramente, o professor utilizar estratégias para identificar o nível de conhecimento dos alunos sobre o contexto e sobre os conteúdos em estudo, para, posteriormente, melhor relacioná-los.

Os documentos PCN e PCN+ apresentam orientações que reforçam o estudo do contexto dos alunos como ponto de partida para a articulação entre conhecimentos das disciplinas de cada uma das áreas. Especificamente no ensino de Química, é proposto que a contextualização contribua para atribuir significações aos conteúdos, viabilizando, assim, o estabelecimento de relações desses conteúdos com outros campos do conhecimento. Para tal, o ensino deve destacar situações problemáticas reais, de maneira crítica, possibilitando ao estudante desenvolver competências e habilidades específicas, como analisar informações, dados, argumentar, concluir, avaliar e tomar decisões (BRASIL, 1999, 2002a).

Uma complementação referente aos currículos se deu com a publicação das Orientações Curriculares para o Ensino Médio (BRASIL, 2006), que aponta a contextualização como um pressuposto importante no ensino de Ciências, uma vez que apresenta o papel de mediar o diálogo entre as disciplinas, principalmente aquelas cujo objeto de estudo abrange 0 contexto real, situações de vivência dos alunos, os fenômenos naturais e artificiais e as aplicações tecnológicas. $O$ documento sugere a contextualização de temas socialmente relevantes para o ensino de Química, como mostra o seguinte trecho:

Defende-se uma abordagem de temas sociais (do cotidiano) e uma experimentação que, não dissociados da teoria, não sejam pretensos ou meros elementos de motivação ou de ilustração, mas efetivas possibilidades de contextualização dos conhecimentos químicos, tornando-os socialmente mais relevantes (BRASIL 2006, p. 117).

Com base nesse panorama, Silva (2007), por meio de pesquisas com professores e análises documentais, dispõe a contextualização no ensino de 
Ciências em três propostas: A primeira proposta de contextualização, segundo o autor, é a exemplificação, em que, por meio de exemplos e fatos inerentes à vida diária do aluno, o professor relaciona fenômenos do contexto discente a conhecimentos científicos. Nesta perspectiva, a aprendizagem deve visar uma melhor compreensão de conceitos científicos. Possível exemplo da ocorrência desta proposta de contextualização ocorre quando o professor se utiliza do preparo de café para ensinar filtração, do preparo de um suco para a compreensão de soluções, ou ainda de uma água fervendo para explicar as mudanças de estado físico da matéria.

A segunda proposta de contextualização adota uma complexidade maior de conhecimentos, já que necessita de uma compreensão crítica, por meio da análise sistemática de como questões científicas e tecnológicas afetam a sociedade. Como estratégia didática, podemos utilizar um tema que considere, fundamentalmente, o estudo de uma questão social, cultural ou tecnológica envolvendo situações amplas e complexas que requeiram uma abordagem interdisciplinar para dar suporte à problematização.

A terceira proposta de contextualização envolve, essencialmente, a perspectiva de intervenção na sociedade. Nesse sentido, a contextualização se desenvolve por intermédio de ações efetivas, com o auxílio de conhecimentos científicos para direcionar a ação em uma comunidade. De acordo com esse pressuposto, a formação do aluno ocorre baseada na iniciativa do seu propósito de modificar a realidade em que se encontra. Exemplo provável desse modelo de contextualização seria uma trilha didática com o intuito de promover uma educação ambiental, removendo lixos ou coletando amostras para análises.

Independentemente da proposta de contextualização assumida, a sua utilização nos parece promover facilidades durante a aprendizagem e a Educação Profissional se faz valer de prerrogativas contextualizadoras como meio eficaz de compreensão de questões relativas ao mundo do trabalho.

\subsection{ENSINO INTEGRADOR}

Segundo Ramos (2008), a modalidade integrada visa formar o profissional por meio da educação orientada pelo trabalho, e, por 
consequência, o currículo escolar é determinado em exigência da formação técnica específica.

O professor Claudio Gomes, pesquisador e coordenador geral do ensino técnico da Escola Politécnica de Saúde Joaquim Venâncio (EPSJV/Fiocruz), em entrevista com Leila Leal à revista Poli, deixa claro que a educação integradora trata de uma educação pelo trabalho, e não para o trabalho. Afirma Gomes:

Não quer dizer que o Ensino Médio ou Fundamental devem ser, necessariamente, profissionalizantes. Mas sim afirmar o trabalho como princípio organizador da concepção de educação em todos os níveis. (POLI, 2011, p. 10).

No âmbito das disciplinas que compõem o currículo de um curso Técnico, na modalidade de ensino integrado, Pacheco (2012) afirma que disciplinas vinculadas às ciências, que estruturam as diferentes profissões, não podem ser fragmentadas, mas deve formar uma unidade, sem separar, assim, técnica e tecnologia.

Reforçando essa perspectiva de ensino integrado, Ramos afirma:

No currículo que integra formação geral, técnica e política, o estatuto de conhecimento geral de um conceito está no seu enraizamento nas ciências como 'leis gerais' que explicam fenômenos. Em razão disso, no currículo integrado nenhum conhecimento é só geral, posto que estruturam objetivos de produção; nem somente específico, pois nenhum conceito apropriado produtivamente pode ser formulado ou compreendido desarticuladamente da ciência básica (RAMOS, 2008. p. 19).

Na realização prática dessa articulação entre disciplinas científicas e as específicas da formação profissional, a interdisciplinaridade e a contextualização são aparatos fundamentais para uma relação entre partes e totalidade. Ramos (2008) ainda afirma que os diversos campos da ciência são representados em disciplinas e quando relacionadas, partindo de recordes da realidade, possibilita compreensão de conceitos. 
O IFMS disponibiliza o Regulamento da Organização DidáticoPedagógica dos Cursos de Educação Profissional Técnica de Nível Médio Integrado, que, em seu capítulo II, ao tratar do currículo, prevê:

Art. 10. A estrutura do Projeto de Curso pode ser
constituída por módulos de ensino que poderão
propiciar certificação de qualificação profissional e/ou
diplomação. As unidades curriculares que constituem
o(s) módulo(s) de ensino devem ser articuladas de
forma a privilegiar a interdisciplinaridade e a
contextualização (IFMS 2014. p. 10).

Ao analisar esse documento, preocupamo-nos em verificar se o IFMS apresentava esta precaução em seu PDI, e observamos que a interdisciplinaridade está prevista em seus princípios filosóficos e teóricometodológicos, também relata que o TCC deve atender a uma perspectiva interdisciplinar e no que tange à contextualização, o documento somente a propõe nas práticas de estágio (IFMS, 2014).

Nesse sentido, quando pensamos em cursos da modalidade integrada, como o curso Técnico Integrado ao Ensino Médio em Informática (TIEMI), pode-se esperar uma maior articulação relacional entre as disciplinas do núcleo comum e as específicas da formação do futuro profissional da informática. Mas, uma forma de promover ações efetivas no curso seria prevê-las em seu PPC e, nesse caso, isso não acontece no PPC do curso TIEMI.

\section{METODOLOGIA}

Buscando identificar ações de prática pedagógica contextualizada e interdisciplinar, no curso TIEMI, procuramos analisar os documentos institucionais que parametrizam as ações pedagógicas no IFMS. Optamos por fazer uma análise qualitativa dos trechos dos textos em que aparecem os termos contextualização e interdisciplinaridade, bem como os seus correlatos. A análise qualitativa evitaria as dificuldades, geralmente encontradas nas pesquisas quantitativas, em atribuir valor nas análises textuais (LÜDKE e ANDRÉ, 1986). Os documentos analisados foram 0 Plano de 
Desenvolvimento Institucional - PDI. 2014-2018 (IFMS, 2014), 0 Regulamento da Organização Didático-Pedagógica dos Cursos de Educação Profissional Técnica de Nível Médio Integrado (IFMS, 2012) e o Projeto do Curso de Educação Profissional Técnica de Nível Médio Integrado em Informática (IFMS, 2010).

Duas disciplinas da matriz do curso, tiveram suas ementas analisadas para que se pudesse extrair possíveis relações interdisciplinares. Em conjunto, o professor de química e o da disciplina técnica, elaboraram e aplicaram uma proposta didática dividida em seis diferentes momentos.Optamos por descrever as intervenções dos dois professores, e também acrescentamos algumas possíveis intervenções para outras disciplinas, como sugestão de ação pedagógica.

O curso TIEMI do IFMS possui, no seu primeiro período, as disciplinas de Química 1 e Organização de Computadores, que por suas características se mostraram apropriadas para possíveis ações interdisciplinares.Ao constatar que a unidade curricular de Química I prevê o estudo de tabela periódica e a unidade curricular de Organização de Computadores prevê o estudo da estrutura básica e conceitos fundamentais de componentes e periféricos de computadores, percebemos a possibilidade de estabelecer relações entre as disciplinas em uma sequência desenvolvida pelos professores responsáveis, e que descreveremos a seguir.

A proposta didática foi prevista para duas aulas de 45 minutos e em sequência uma da outra. Foi elaborada em conjunto pelos professores das disciplinas e aplicada em turmas do primeiro semestre do TIEMI, na sala de laboratório de hardware do IFMS campus Coxim. Os alunos foram dispostos em sete grupos de cinco componentes cada, distribuídos em bancadas, que foram previamente preparadas para a aula. Cada grupo recebeu o mesmo kit de partes de computadores para análise, contendo: gabinete, fios e cabos, tela de LCD, processador, placas de circuitos integrados, disco rígido, bateria de íon lítio e placa mãe.

No desenvolvimento da aula, o professor da disciplina técnica descreve as partes integrantes do computador, suas funções e características, enquanto o professor de Química explica a presença de elementos e 
compostos químicos em cada periférico, mostrando quais propriedades desse material justificaria o seu uso em computadores.Cada constituinte foi descrito na aula em momentos distintos.

\section{1ำ momento - descrição do processador:}

Abordagem para o professor da disciplina técnica:

O processador é uma das partes mais fundamentais de um computador, podemos dizer que é o "cérebro" do computador (PC). É ele um dos principais responsáveis pela velocidade de processamento de dados e, por isso, uma das partes mais importantes. Todo esse processamento de informações ocorre por meio de transistores que permitem ou não a passagem de corrente elétrica, e isso é interpretado como linguagem binária 0 e 1, que é a linguagem de máquina.

Abordagem do professor de Química:

Devido à grande importância das funções presentes no processador, alguns circuitos, local onde ocorre a troca de informações, exigem propriedades especiais, pois, necessitamos de um material que seja bom condutor, resistente a ataques químicos, como a oxidação e que suporte altas temperaturas. O Ouro possui elevada condutividade elétrica, ficando atrás apenas da Prata e do Cobre. Entretanto, esse metal nobre possui maior valor de ionização que os dois supracitados, o que o torna menos reativo evitando, então, possíveis ataques químicos externos, como a ferrugem. Assim, muitas linhas do circuito integrado, pinos, terminais e barramentos dos processadores são revestidas com Ouro, uma fina camada que protege ligas metálicas contra ações oxidantes, mantendo uma ótima condutividade, o que minimiza riscos de haver mau contato entre os componentes.

Os transistores são feitos de Silício, devido à sua característica semicondutora quando combinado a outros elementos. O Silício, na verdade, em sua forma pura, é um isolante; contudo, após sofrer um processo 
denominado dopagem eletrônica, torna-se um semicondutor e serve perfeitamente aos propósitos da eletrônica na atualidade. A dopagem consiste em adicionar impurezas a um elemento químico para dar-lhe propriedades de semicondução. São dois os tipos de camadas de Silício: as do tipo $\mathrm{N}$ - dopadas com átomos como o Fósforo, e as do tipo $\mathrm{P}$ - dopadas com átomos como o Boro. Normalmente, um transistor é montado em camadas do tipo N-P-N (NASCIMENTO, 2004). Devido a essa propriedade semicondutora, quando o usuário dá uma ordem ao computador, há duas possibilidades: a primeira é a de não mudar nada, pois não passa corrente pelo transistor, comportando-se este como se fosse um interruptor desligado; a segunda possibilidade é de a ordem disparar uma carga positiva na base do transistor, passando uma corrente elétrica, agindo como se o transistor fosse um interruptor ligado. Quando ocorre a passagem de corrente, o transistor é representado na linguagem da máquina pelo número 1. Quando não ocorre a passagem de corrente significa, na linguagem da máquina, o número 0 .

Possíveis intervenções em outras disciplinas:

Devido à importância econômica do Ouro para muitos países, pode haver a intervenção do professor de Geografia, disciplina em que questões como esta, dentre outras, podem ser trabalhadas. Historicamente, o Ouro sempre esteve presente na formação de nosso país, e, particularmente, na região de Coxim, local em que desenvolvemos o nosso trabalho, por ter sido esta cidade um entreposto dos monçoeiros da rota do Ouro de Cuiabá, tais questões permitiriam a abordagem do professor de História. Tendo em vista que a exploração do Ouro pode causar impactos ao meio ambiente, esta questão poderá ser discutida, também, pelo professor de Biologia. No que concerne à exploração do Silício, questões geopolíticas podem ser consideradas, como a formação do Vale do Silício nos Estados Unidos, o grande desenvolvimento industrial e tecnológico na Índia, Coreia do Sul, Japão, Singapura etc. $O$ conteúdo de semicondutores pode ser abordado pelo professor de Física. 


\section{2o momento - descrição do Disco Rígido:}

Abordagem para o professor da disciplina técnica:

O disco rígido, comumente chamado de Hard Disk (HD), é um dispositivo capaz de armazenar dados no PC. No HD é armazenado qualquer tipo de informação, podendo ser um simples arquivo, como também dados utilizados pelo sistema operacional. O HD funciona como a memória do computador, entretanto, diferente da memória RAM, essa memória não apaga os dados quando o PC é desligado.Dentro do disco rígido, os dados são gravados em discos magnéticos. O nome "disco rígido" vem justamente do fato de os discos internos serem extremamente resistentes. Os discos ficam sob o eixo, que é responsável por fazê-lo girar. Os HDs mais comuns são capazes de alcançar entre 5.600 a 7.200 rotações por minuto, embora existam modelos que chegam até os 10.000 RPM (MORIMOTO 2011).

Abordagem do professor de Química:

Devido às altas velocidades de rotação com que os discos chegam, é necessário que sejam feitos de materiais leves; nesse ponto entra o alumínio, que possui uma densidade baixa. Logo, seu peso específico é bem inferior em relação aos outros metais. Em alguns casos não se utiliza o alumínio puro, mas ligas que contêm o material. O alumínio é o metal mais abundante da crosta terrestre, e outra possibilidade de utilizá-lo é aproveitando suas propriedades antimagnéticas, característica que impede interferências no ferromagnetismo do Óxido de Ferro. Durante o processo de gravação, o campo magnético gerado pelos ímãs presentes nas cabeças faz com que as moléculas de ferro, na forma de óxidos, presentes na superfície magnética dos discos se reorganizem, alinhando seus polos negativos com os polos positivos da cabeça. Da mesma forma, os polos positivos se alinham com os negativos.O elemento químico Ferro é utilizado na gravação de dados no HD, devido suas propriedades ferromagnéticas. Duas características em sua 
estrutura permitem o seu ferromagnetismo: o fato de apresentar elétrons desemparelhados e o arranjo dos átomos, que estão a uma distância perfeita.

Possíveis intervenções em outras disciplinas:

O professor de Física pode abordar as questões que envolvem eletricidade, magnetismo, cinemática e dinâmica, pois são conteúdos amplamente trabalhados nessa disciplina. A exploração do minério de Ferro pode ser abordada tanto economicamente, por se tratar de um importante commodity, como geologicamente, nas diferentes formações da crosta terrestre. Esta temática poderá ser desenvolvida tanto pelo professor de História quanto pelo de Geografia. Reportagens de revistas econômicas,em língua inglesa, que tratam das questões relativas à produção, exportação e industrialização do minério de Ferro poderiam ser utilizadas como apoio didático-pedagógico nas aulas pelo professor de inglês. O professor de Química, juntamente com o de Biologia, poderia abordar questões relativas à reciclagem do alumínio, por ser o Brasil o país que está no topo do ranking da reciclagem desse metal, e o quanto isso diminui o impacto ambiental, já que a extração do alumínio exige uma quantidade de energia muito grande.

3ำ momento - descrição de fios, cabos e gabinete:

Abordagem para o professor da disciplina técnica:

Os fios e cabos presentes em um computador têm as funções de conduzir eletricidade e transmitir dados. Os fios visam acionar e alimentar tanto o computador quanto periféricos, como, por exemplo, o cabo que alimenta o computador. Dentre os fios que objetivam transmitir dados, podemos citar os de par trançado, cabos coaxiais e sata. A bitola do fio ou cabo depende da corrente que será conduzida. $A$ "caixa" externa do computador é o gabinete, que serve de sustentação e proteção aos dispositivos internos que compõem o micro. Todos esses 
materiais precisam ser isolados para evitar a perda de corrente elétrica e possíveis curtos.

Abordagem do professor de Química:

Quanto ao material condutor presente nos cabos e fios, é comum o uso do cobre. A escolha deste metal se deve à sua excelente condutividade elétrica somente superada pela Prata, porém, com o custo de utilização menor (ADVFN, 2014).Tanto o gabinete quanto o revestimento dos fios possuem em sua composição uma grande quantidade de plásticos com a finalidade de isolar e proteger. Durante a produção desses plásticos utilizados em computadores são acrescentados aditivos antichamas, que têm a função de inibir, ou, quando possível, eliminar a propagação do fogo em um material. Isso se torna altamente necessário quando uma peça está exposta a temperaturas elevadas ou correntes elétricas, fatores que, somados à flamabilidade de boa parte dos polímeros, podem apresentar um resultado indesejável, como incêndios (RODA, 2014).

Quando um material se decompõe termalmente, há dois resíduos: um gás, que é o que provoca a chama, e uma parte carbonizada. Quando tentam criar um plástico que não queima, o objetivo é gerar a maior quantidade possível de resíduo carbonizado - o que significa menos chama e compostos voláteis. Para diminuir esse risco de chamas, a indústria adiciona compostos químicos "retardadores de queima", normalmente moléculas bromadas, devido à sua alta reatividade.

O bromo reage sinergicamente com o antimônio, também adicionado no material, quando aquecidos, retardam as chamas por: resfriamento - as reações são endotérmicas, o que resfria o ambiente, ou seja, esfriam ambientes a temperaturas abaixo das requeridas para a ocorrência de pirólise; por formação de camada protetora - em que a fase condensada do substrato combustível é isolada da fase gasosa por uma camada protetora sólida ou gasosa. O processo de retroalimentação térmica é retardado ou interrompido, o que causa o resfriamento da fase condensada, inibindo a pirólise. A camada protetora também reduz ou impede a transferência de 
gases combustíveis para a região de queima gasosa, o que contribui para a inibição das reações de combustão (GALLO e AGNELLI, 1998).

Possíveis intervenções em outras disciplinas:

O conteúdo de resistência de metais condutores pode ser abordado pelo professor de Física em eletrodinâmica, ao tratar da lei de Ohm. Peças de computadores em desuso estão sendo enviadas para países pobres, principalmente da África, com a disfarçada pretensa "inclusão digital", ou para fins de "alimentar a indústria recicladora dessas regiões" (OLIVEIRA et. al. 2010), o que, na verdade, é uma transferência de Lixo. Tal abordagem pode ser realizada pelo professor de Sociologia, pois as populações desses países reaproveitam os metais dessas peças por meio de processos de grandes impactos ambientais, que também podem, por sua vez, ser abordados pelo professor de Biologia.

\section{4º momento - descrição da bateria Íon Lítio:}

Abordagem para o professor da disciplina técnica:

As baterias de lítio são as mais modernas do mercado de computadores portáteis conforme mostrado. Sua voltagem varia de 3,0 a 3,5 V. São baterias do tipo recarregável, pois seu processo de descarga é reversível, bastando aplicar uma corrente contínua por meio de um transformador. São as baterias com melhor custo-benefício do mercado, pois conseguem armazenar 0 dobro ou 0 triplo de energia de baterias convencionais, ocupando o mesmo volume e sendo mais leves.

Abordagem do professor de Química:

Essas baterias levam esse nome porque o agente responsável pelo fornecimento de energia é o Íon Lítio $\left(\mathrm{Li}^{+}\right)$, que é altamente reativo devido à sua alta eletropositividade, aumentando, assim, a capacidade de 
armazenamento de energia. Como o Lítio possui o potencial padrão mais negativo de todos os elementos, ele pode produzir uma alta capacidade de armazenamento de energia quando usado em células galvânicas; suas baterias possuem uma grande capacidade de manutenção de carga, o que aumenta a sua vida útil. Uma bateria de íon Lítio consegue suportar de 200 a 300 ciclos de carga/descarga, em média. Além disso, como a densidade desse elemento é muito baixa, baterias de íon Lítio são leves (ATKINS, 2012). Outra vantagem do Lítio é o fato de não ser tóxico, diferente de algumas baterias feitas, por exemplo, de Cadmo, que também possui potencial padrão negativo bem baixo, mas são muito poluidoras.

Possíveis intervenções em outras disciplinas:

O descarte incorreto de pilhas e baterias pode ser abordado pelo professor de Biologia, juntamente com o professor de Química. O professor de Física pode tratar de questões acerca do sentido e tipos de corrente em um sistema elétrico. A formação geológica dos depósitos de Lítio na Bolívia e no Chile também pode ser abordada pelo professor de Geografia (WRIGHT, 2010).

\section{5 momento - descrição das telas de LCD:}

Abordagem para o professor da disciplina técnica:

A tecnologia das telas de LCD, ou telas de cristal líquido (Liquid Crystal Display), disseminou-se rapidamente no mercado. Substituindo as antigas telas de tubos de raios catódicos (CRT), essas telas são mais leves, finas e econômicas. Todas essas vantagens são devidas às novas tecnologias que envolvem o LCD. As telas de LCD oferecem diversas vantagens sobre outros monitores, pois produzem pouca (ou nenhuma) radiação nociva, o que causa menos danos aos olhos e ocupa menos espaço; são completamente planas, não perdendo imagens dependendo do ângulo de visão, e são mais leves. 
Abordagem do professor de Química:

Os eletrodos das telas de LCD são formados por Óxido de Índio combinado com estanho e recebem a denominação ITO, do inglês Indium-Tin Oxide. O Índio é um metal do quarto período pertencente ao grupo 13 , enquanto o estanho, também do quarto período, pertence ao grupo 14. Tratase de um material pertencente a uma classe denominada Óxidos Condutores Transparentes (TCO's, de TransparentConductive Oxides).

Esta propriedade de transparência é de extrema relevância, já que grande parte dos materiais condutores não o é, logo, esses óxidos não atrapalham a resolução das imagens na tela. Essa classe de óxidos tem a capacidade de refletir comprimentos de ondas na faixa do infravermelho, propriedade óptica que impede o aquecimento do cristal líquido, que é muito sensível a altas temperaturas, além de oferecer baixa resistência para a condução de eletricidade.

Essa característica dos eletrodos ITO permite que pouca corrente seja suficiente para ativar as informações nos cristais líquidos, portanto, o gasto total de energia é menor e, consequentemente, aquece menos o meio (DAMIANI 2010). Como o Índio é um material escasso na natureza, hoje muito se preocupa com a reciclagem das telas de LCD e com a produção de outros TCO's, como Óxido de Zinco ( $\mathrm{ZnO}$ ) dopado e Óxido de Estanho $\left(\mathrm{SnO}_{2}\right)$ dopado. Entretanto, nenhum material possui a boa condutividade e qualidades ópticas como o ITO possui.

Possíveis intervenções em outras disciplinas:

Materiais translúcidos, opacos, polarização da luz e a reflexão podem ser abordados pelo professor de Física no conteúdo de ótica, em transmissão de calor, momento em que o professor poderia tratar as questões relativas ao infravermelho.

60 momento - descrição da Placa Mãe: 
Abordagem para o professor da disciplina técnica:

A placa mãe, também conhecida como "motherboard" ou "mainboard", é basicamente a responsável pela interconexão de todas as peças que formam o computador. O HD, a memória, o teclado, o mouse, a placa de vídeo, enfim, praticamente todos os dispositivos precisam ser conectados à Placa Mãe para formar o computador. Uma placa mãe precisa ter uma base sólida, onde serão adicionados os demais itens. Essa base é conhecida como placa de circuito impresso, que serve de suporte para os componentes de qualquer equipamento eletroeletrônico. Os componentes estão interligados por meio de trilhas que conduzem a corrente elétrica entre os periféricos, viabilizando seu funcionamento (FRANÇA E BONFIM 2010).

Abordagem do professor de Química:

Quanto ao material condutor presente nas trilhas das placas de circuitos impressos é empregado o cobre, conforme já relatado anteriormente. Porém, além desta característica condutora, o cobre permite a produção de folhas de pequena espessura por ser um material de grande maleabilidade $e$ essa característica pode ser explorada pelo professor, por ser uma propriedade dos metais.

Possíveis intervenções em outras disciplinas:

O funcionamento da Placa Mãe, juntamente com o processador, pode compor uma relevante analogia para a compreensão do funcionamento do corpo humano. O professor de Biologia, ao abordar conteúdos relacionados ao cérebro e às terminações nervosas da medula, poderia traçar um paralelo entre um processador e a Placa Mãe. 


\section{RESULTADOS E DISCUSSÃO}

No decorrer das análises dos documentos que norteiam a EPT, foi possível perceber uma consonância entre os documentos oficias no âmbito nacional e os documentos institucionais do IFMS no que tange à interdisciplinaridade e à contextualização, uma vez que esses recursos são previstos na modalidade de educação integrada. Entretanto, o PPC do curso TIEMI e as ementas de suas disciplinas, estão construídos de forma que ações contextualizadas ou interdisciplinares não sejam favorecidas, fator que causa preocupação à prática docente, pois, tendo em vista que tal documento parametriza o curso, isso poderia implicar em uma ciência química fragmentada e isolada de outros fenômenos.

Nossa proposta didática, procurou abranger questões tecnológicas a partir da articulação entre as disciplinas de Química e Organização de Computadores. A troca de conhecimentos entre os professores envolvidos nas disciplinas em questão, foi imprescindível para o desenvolvimento da aula, já que cada um destes pôde conhecer melhor a disciplina do outro, culminando em um melhor preparo da aula, promovendo uma proposta interdisciplinar entre os conteúdos de tabela periódica, de estudo sucinto de materiais e o estudo da estrutura básica e conceitos fundamentais de componentes e periféricos de computadores.

Por constituir em uma disciplina em que a abordagem tecnológica é evidenciada, Organização de Computadores permitiu a articulação para que os professores pudessem discorrer sobre os conteúdos de Informática e Química, porém a seleção dos conteúdos a serem abordados não foi tarefa muito fácil, uma vez que o tempo disponível para as reuniões de preparo de aula foi escasso.Como o curso de TIEMI é técnico seus discentes almejam a formação na área de Informática, isso facilita a construção de contextos, fator que contribuiu para maior participação e interesse dos estudantes no decorrer da ação pedagógica, e parece ter proporcionado aos alunos uma melhor compreensão dos fatores envolvidos. 
A apresentação da proposta da aula causou surpresa aos alunos, pois nunca haviam participado de uma aula com dois professores trabalhando simultaneamente. Após a introdução, o professor de informática discorreu acerca do processador, o que desprendeu um pouco mais de tempo, possivelmente devido à relevância desse periférico. Quando o professor de Química interveio indicando as propriedades do Silício e do Ouro, os estudantes demostraram bastante curiosidade sobre a presença desse segundo elemento no processador, o que permitiu uma maior ação contextualizante.

Quando o professor de informática explanava acerca do disco rígido, vários alunos indagaram sobre as funções desse componente. Antes que o professor de Química falasse qual seria o material presente nesse periférico, foram apresentadas algumas características que, obrigatoriamente, esse material deveria conter, como leveza, resistência à oxidação e condutividade elétrica. Os estudantes, então, naturalmente indicaram que esse material poderia ser o metal Alumínio, e isso foi perceptível devido às várias manifestações dos estudantes, o que seria um indicativo de que houve a construção de conhecimento.

Quando o professor de informática explanou acerca das telas de LCD, os alunos ficaram surpresos ao notar que estas são compostas por várias chapas. Quando o professor de Química abordou sobre a liga de Índio com Estanho os estudantes manifestaram surpresa por existir metais nesses materiais transparentes. Este fato foi explorado pelo professor de Química, pois uma das características inerentes a essas telas é justamente adequada transparência aliada à boa condutividade elétrica.

Durante a aula, vários foram os estudantes que realizaram indagações sobre diversos assuntos, como a presença de Lítio nas baterias, o descarte correto de pilhas e baterias, os impactos ambientais devido a descartes inadequados e até questões sobre os processos biocomulativos de metais pesados. Ao término da ação pedagógica, alguns alunos fizeram, ainda, questionamentos sobre cristal líquido e suas propriedades, as diferentes condutividades em sólidos, líquidos e gases e sobre a remoção do ouro presente em processadores. Ainda durante conversas com os estudantes, 
estes relataram que "nunca havia participado de uma aula daquele modo", e que "aulas assim poderiam acontecer sempre".

O professor de Informática, em seu relato sobre nossa proposta interdisciplinar e contextualizada, deixa claro que foi notável o maior interesse da turma pelos conteúdos, devido, principalmente, ao trabalho em conjunto em sala de aula, apesar de sempre, em suas aulas, incentivar os alunos a procurar professores de outras disciplinas a respeito de fenômenos químicos ou físicos que estão envolvidos nos periféricos. O professor nunca havia se envolvido com ações parecidas como esta, e ressaltou que deveria "ampliar tal prática”. Ao relatar que os alunos já haviam estudado um pouco sobre os conteúdos envolvidos, sugeriu que realizássemos outra prática semelhante à sucedida, antes da apresentação dos conteúdos, para poder comparar as impressões dos estudantes.

\section{CONCLUSÃO}

Durante a pesquisa, ficou evidente a necessidade do professor de Química conhecer processos químicos envolvidos na área de informática, uma vez que tal articulação entre as disciplinas são previstas na modalidade de ensino integrado. Nossa proposta mostra que essa articulação é possível, e a escolha do conteúdo de tabela periódica nos parece ser uma opção adequada para esse fim.

Diante da abordagem apresentada, foi possível estabelecer relações interdisciplinares e contextualizadas entre conteúdos de Química e a sua aplicação a realidades da informática. Os estudantes participantes da aula puderam compreender propriedades dos elementos e materiais conforme seu uso em componentes de computador. As reações dos estudantes evidenciam essa questão e indica que a prática utilizada foi eficaz no que tange a contextualização dos conteúdos trabalhados nas aulas.

Foi possível perceber que a ação interdisciplinar promovida pela intervenção despertou interesse nos estudantes em aprofundamento dos seus conhecimentos em Informática e assuntos relativos à tecnologia da informação. O professor de Informática também pôde perceber uma maior motivação dos estudantes, fator que reforça a ideia de que a 
interdisciplinaridade e a contextualização são ferramentas adequadas ao ensino profissional e que nossa ação pedagógica passa a ser mais uma contribuição nesse sentido.

\section{REFERÊNCIAS}

ADVFN. Preço e cotação das principais Commodities e Mercadorias da BM\&F e mundo.2015. Disponível em:

<http://www.br.advfn.com/commotidies>. Acesso em: 24 jun. 2018.

ATKINS, P.; JONES, L. Princípios de química: questionando a vida moderna e o meio ambiente. Porto Alegre: Bookman, 2012.

BRASIL. Ministério da Educação. Parâmetros Curriculares Nacionais do Ensino Médio. Brasília: MEC/SEMTEC, 1999.

BRASIL. Ministério da Educação. Referenciais Curriculares Nacionais da Educação Profissional de Nível Técnico. Área Profissional: Informática. Brasília. 2000. Disponível em:

$<$ http://pronatec.mec.gov.br/cnct/et_informacao_comunicacao/>. Acesso em: 15 jun. 2018.

BRASIL. Ministério da Educação. PCN + Ensino Médio: Orientações educacionais complementares aos Parâmetros Curriculares Nacionais. Brasília: MEC/SEMTEC, 2002a.

BRASIL. Ministério da Educação. Resolução CNE/CP no 03, de 18 de Dezembro de 2002; Brasília, 2002b. Disponível em: $<$ www.portal.mec.gov/setec/arquivos/pdf_legislação/rede/legisla_rede _resol03.pdf.>. Acesso em: 18 jun. 2018.

BRASIL. Ministério da Educação. Orientações Curriculares para o Ensino Médio. Volume 2. Ciências da natureza, matemática e suas tecnologias. Brasília, 2006.

BRASIL. Acesso a Informação. Câmpus que ofertam o curso Técnico Integrado em Informática. Brasília. 2014. Disponível em: <http://www.acessoainformacao.gov.br/>. Pedido realizado em: 08 dez. 2014, conforme protocolo número 23480014636201492.

DAMIANI, L. R. Filmes de óxido de índio dopado com estanho depositados por magnetronsputtering. Dissertação de mestrado. Universidade de São Paulo - USP Ano de defesa 2010.

FRANÇA, A.; BONFIM, M. Documento auxiliar ao manual técnico da circuibras para o desenvolvimento de circuitos impressos. UFPR Departamento de Engenharia Elétrica. 2010 
GALLO, J, B.; AGNELLI. J. A. M. Aspectos do comportamento de polímeros em condições de incêndio. Polímeros. 1998, vol.8, n.1, pp. 23-38. ISSN 0104-1428. Disponível em:<http://www.scielo.br/pdf/po/v8n1/8326.pdf>. Acesso em: 28 mar. 2018.

IFMS. Plano de Desenvolvimento Institucional - PDI. 2014-2018. 2014. Disponível em: <http://www.ifms.edu.br/pdi/>. Acesso em: 17 mai. 2018.

IFMS. Projeto do Curso de Educação Profissional Técnica de Nível Médio Integrado em Informática. 2010. Disponível em: $<$ http://www.ifms.edu.br/centrais-de-conteudo/documentosinstitucionais/projetos-pedagogicos/projetos-pedagogicos-dos-cursostecnicos/projeto-pedagogico-do-curso-tecnico-em-informatica-coxim.pdf $>$. Acesso em: 17 jun. 2018.

IFMS. Regulamento da Organização Didático-Pedagógica dos Cursos de Educação Profissional Técnica de Nível Médio Integrado. 2012. Disponível em: <http://www.ifms.edu.br/wpcontent/uploads/2011/05/Organiza\%C3\%A7\%C3\%A3o-Did\%C3\%A1ticoPedag\%C3\%B3gica.pdf>. Acesso em: 17 mai. 2018.

LÜDKE, M.; ANDRÉ, M. E.D.A. Pesquisa em educação: abordagens qualitativas. São Paulo, Editora Pedagógica e Universitária, 1986. 99p.

MORIMOTO, C. E. Hardware, o Guia Definitivo. São Paulo: GDH Press e Sul Editores, 2011. Disponível em:

<http://www.hardware.com.br/guias/hds/como-hds-funcionam.html>. Acesso em: 04 abr. 2018.

NASCIMENTO, C. A. Princípio de Funcionamento da Célula Fotovoltaica. Monografia de Especialização. Universidade Federal de Lavras - MG. 2004.

OLIVEIRA, R. da S; GOMES, E. S.; AFONSO, J. C. O Lixo Eletroeletrônico: Uma Abordagem para o Ensino Fundamental e Médio.Química Nova Na Escola. Vol. 32, № 4, 2010.

PACHECO, E. Institutos Federais uma revolução na educação profissional e tecnológica. 1를 Ed, Moderna. Brasília, 2011.

PACHECO, E. Secretaria de Educação Profissional e tecnológica do ministério da educação. Perspectivas da educação Profissional técnica de nível médio. Proposta de Diretrizes Curriculares Nacionais. Moderna. Brasilia. 2012.

POLI. Educação Profissional e Ensino Médio Integrado no Brasil: um balanço das conquistas e reivindicações. Revista Poli.№ 15, jan-fev 2011, Disponível em: <http://www.epsjv.fiocruz.br/upload/Edicoesrevistapoli/R17.pdf>. Acesso em: 24 jun. 2018. 
RAMOS, M. Concepção de Ensino Médio Integrado. Secretaria de Educação do Estado do Paraná, 2008. Disponível em:

<http://www.iiep.org.br/curriculo_integrado.pdf>. Acesso em: 20 jun. 2018.

RODA, D. T. Aditivos Retardantes de Chamas. 2014. Disponível em:

$<$ http://www.tudosobreplasticos.com/aditivos/antichamas.asp>. Acesso em: 15 mar. 2018.

SILVA, E. L. da. Contextualização no ensino de química: idéias e proposições de um grupo de professores. Dissertação de mestrado apresentada ao Instituto de Física. USP. 2007.

THIESEN, J. da S. A interdisciplinaridade como um movimento articulador no processo ensino-aprendizagem. Rev. Bras. Educ., vol.13, no.39.Dez, 2008.

WRIGHT, L. Sonhos de lítio. A Bolívia se tornará a Arábia Saudita da era do carro elétrico? Revista Piauí. 2010. Disponível em:

$<$ http://revistapiaui.estadao.com.br/edicao-45/questoes-energeticas/sonhosde-litio >. Acesso em: 24 jun. 2018. 